\title{
Synthetic biodegradable hydrogel (PleuraSeal) sealant for sealing of lung tissue after thoracoscopic resection
}

\author{
Amulya K. Saxena, MD, Graz, Austria
}

Postoperative air leaks are a major cause of morbidity after lung resections. A variety of biologic and synthetic materials have been used to seal resected lung tissue to address this problem; however, none of the products have been proved effective. Between the 2 groups, synthetic materials have found a preference because they overcome the issues that are associated with the manufacture, storage, and application of biologic substitutes. ${ }^{1,2}$ The use of a novel synthetic biodegradable hydrogel that can be applied as a spray to seal lung tissue after thoracoscopic resection is presented.

\section{CLINICAL SUMMARY}

A 14-year-old female patient presented with recurrent pneumothorax caused by rupture of a left solitary apical pulmonary bleb. A thoracoscopic approach was chosen to manage the pathology. The patient was placed in a right- lateral decubitus position, and the lesion was identified with a 5 -mm $30^{\circ}$ scope. The tissue around the 3-cm-diameter bleb was held with graspers and was resected with endoscopic linear staplers, after which the hydrogel sealant was used prophylactically. PleuraSeal lung sealant (Covidien, Mansfield, Mass) was applied as a spray on the edge of the stapled pulmonary tissue by using the MicroMist applicator (Covidien) through a 5-mm port. The MicroMist applicator is a 1.5 -cm-long and 3.3-mm-diameter multilumen cannula that uses filtered air to spray the sealant and is used in conjugation with a confluent surgical air pump (Figure 1). The PleuraSeal formed a visible blue seal as its 2 liquid components were sprayed on the site of resection and set as a gel (Figure 2). No chest tube was placed. The patient was discharged after 3 days, and regular follow-up examinations during a 1-year period after surgical intervention were uneventful (no pneumothorax or fluid accumulations).

\footnotetext{
From the Department of Pediatric and Adolescent Surgery, Medical University of Graz, Graz, Austria.

Disclosures: None.

Received for publication Sept 22, 2008; revisions received Oct 13, 2008; accepted for publication Nov 2, 2008; available ahead of print March 27, 2009.

Address for reprints: Amulya K. Saxena, MD, Department of Pediatric and Adolescent Surgery, Medical University of Graz, Auenbruggerplatz 34, A-8036 Graz, Austria (E-mail: amulya.saxena@meduni-graz.at).

J Thorac Cardiovasc Surg 2010;139:496-7 0022-5223/\$36.00

Copyright (C) 2010 Published by Elsevier Inc. on behalf of The American Association for Thoracic Surgery

doi:10.1016/j.jtcvs.2008.11.003
}

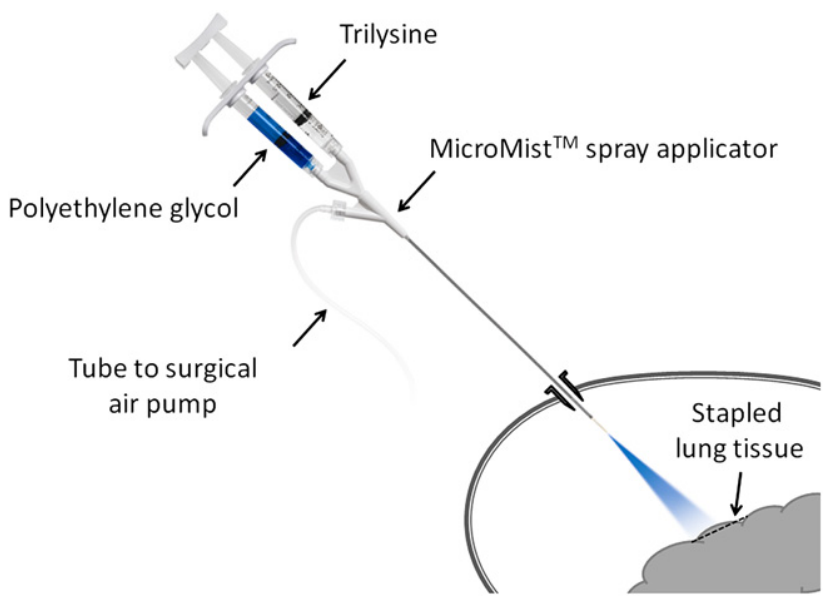

FIGURE 1. The PleuraSeal lung sealant system. The 2 components, polyethylene glycol and trilysine, are sprayed with the MicroMist spray applicator, which is attached to a surgical air pump. The applicator can be passed through a port, and the tip is positioned at a distance of $2 \mathrm{~cm}$ from the tissue site to be sealed.

\section{DISCUSSION}

PleuraSeal is intended for use as an adjunct to the standard closure techniques of underlying pulmonary parenchyma and visceral pleura. It uses advanced hydrogel technology to provide an immediate airtight seal that is effective during surgical intervention and throughout the lung healing period. The seal is maintained over a 4- to 8-week period, after which the hydrogel hydrolyzes to liberate polyethylene glycol (PEG) molecules, which are cleared by the kidneys. PleuraSeal is a $100 \%$ synthetic biodegradable hydrogel that eliminates the risk of allergic reaction, immune response, and viral transmission. Because it is an inert material, it does not support bacterial growth. ${ }^{3}$ The absence of latex in this hydrogel furthermore permits its safe use in patients with known allergy to latex. PleuraSeal is stored at or less than $25^{\circ} \mathrm{C}$, which makes the transport, storage, and use of its components easier than those of fibrin glue.

The PleuraSeal surgical sealant system consists of 2 liquid components: PEG ester and trilysine amine. The first component, PEG, is a water-soluble, nontoxic, and biocompatible component with reactive linkages. PEG is supplied as a transparent blue solution and imparts the blue color to the polymerized hydrogel. The second component, trilysine, is sourced from L-lysine, which comes from the fermentation of cane molasses or tapioca starch and is plant derived, but the final trilysine product is also considered synthetic. 


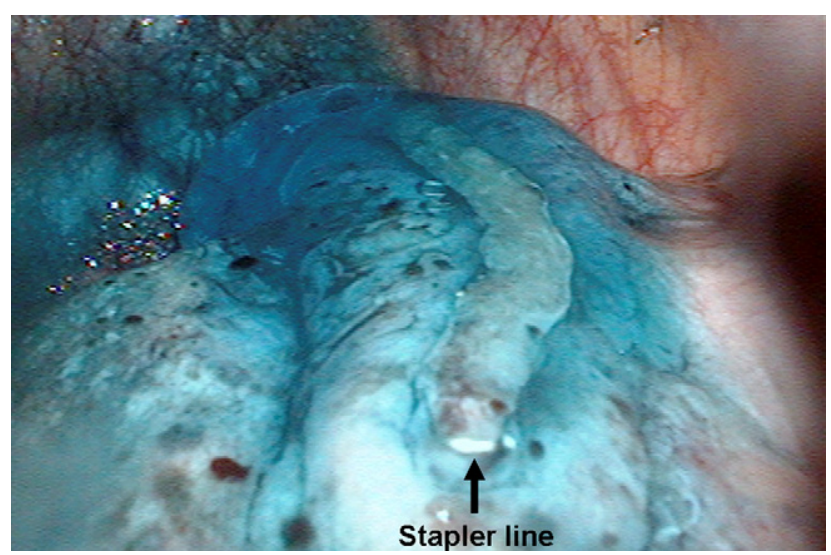

FIGURE 2. Thoracoscopic view of the transparent blue seal after spray application of PleuraSeal lung sealant at the site of pulmonary tissue resection (with an endoscopic linear stapler).

When PEG and trilysine solutions are mixed, they polymerize almost instantaneously to form a 3-dimensional absorbable hydrogel. ${ }^{4}$ The polymerization is a gentle process on tissue with no exothermic reaction and minimal tissue response. The rapid influx of the liquid form of PEG and trilysine into tissue crevices enables hydrogel formation that has a strong mechanical bond with underlying tissue. The combination of high cohesive strength and flexibility of the hydrogel renders it the capability to accommodate natural expansion and contraction of the underlying lung tissue. ${ }^{5}$

For proper spray application during thoracoscopic procedures, the MicroMist applicator tip should be held $2 \mathrm{~cm}$ from the target site, and the sealant should be applied in a way to create a 1- to 2-mm-thick hydrogel. The application site should be prepared by removing all blood and fluids before spraying. When compared with the injection technique, the spray applicator enables uniform spraying of the sealant to cover a larger surface area and enables paucity between spray intervals without clogging of the applicator tip or denaturing of the sealant components.

PleuraSeal has received the CE mark (Conformité Européenne) for lung sealing and has been available in the European Union since 2006; however, at present, it is not for sale in the United States. A single-use application kit costs approximately $€ 400$. PleuraSeal offers a novel offthe-shelf synthetic biodegradable lung sealant that can be applied as a visible blue-colored spray and can be used as a prophylactic adjunct in thoracoscopic lung procedures.

\section{References}

1. Fabian T, Federico JA, Ponn RB. Fibrin glue in pulmonary resection: a prospective randomized, blinded study. Ann Thorac Surg. 2003;75:1587-92.

2. Torchiana DF. Polyethylene glycol based synthetic sealants: potential uses in cardiac surgery. J Card Surg. 2003;18:504-6.

3. Shingel K, Di Stabile L, Marty JP, et al. Inflammatory inert poly(ethylene glycol)protein wound dressing improves healing responses in partial- and full-thickness wounds. Int Wound J. 2006;3:332-42.

4. Royce Hynes S, McGregor LM, Ford Rauch M, et al. Photopolymerized poly (ethylene glycol)/poly(L-lysine) hydrogels for the delivery of neural progenitor cells. J Biomater Sci Polym Ed. 2007;18:1017-30.

5. Almany L, Seliktar D. Biosynthetic hydrogel scaffolds made from fibrinogen and polyethylene glycol for 3D cell cultures. Biomaterials. 2005;26:2467-77.

\title{
The application of nitinol thermoreactive Flexigrips for late post-cardiac surgery sternal instability
}

\author{
Hunaid A. Vohra, MRCS, MD, Robert N. Whistance, MRCS, Marcob Bolgeri, MRCS, and \\ Geoffrey M. K. Tsang, MD, FRCS(CTh), Southampton, United Kingdom
}

Median sternotomy is the most frequently used incision in cardiac surgery. Sternal instability is a chronic complication

\footnotetext{
From the Wessex Cardiothoracic Centre, Southampton University Hospitals NHS Trust, Southampton, United Kingdom.

Disclosures: None.

Received for publication Nov 22, 2008; accepted for publication Dec 6, 2008; available ahead of print May 11, 2009.

Address for reprints: Geoffrey M. K. Tsang, MD, FRCS(CTh), Wessex Cardiothoracic Centre, Southampton University Hospitals NHS Trust, Southampton General Hospital, Tremona Road, Southampton, United Kingdom (E-mail: geoff.tsang@suht.nhs.uk). J Thorac Cardiovasc Surg 2010;139:497-9 0022-5223/\$36.00

Copyright $(2010$ Published by Elsevier Inc. on behalf of The American Association for Thoracic Surgery

doi:10.1016/j.jtcvs.2008.12.003
}

following malunion or nonunion. This is traditionally managed by reopening the sternum completely, removing fractured or loose metalwork, and rewiring. Reoperation may be hazardous due to adhesions, adjacent right ventricle, and patent grafts. We report for the first time the application of nitinol thermoreactive Flexigrips (Preasidia SRL, Bologna, Italy) in the management of sternal instability without the need to enter the mediastinum.

\section{CLINICAL SUMMARY \\ Patient 1}

An 80-year-old man with $\mathrm{FEV}_{1}$ of $0.8 \mathrm{~L}$ was admitted with unstable angina. After an urgent coronary angiogram, he underwent quadruple coronary artery bypass grafting $(\mathrm{CABG}$; 